\title{
The Effect of Nanoclay on Dust Generation during Drilling of PA6 Nanocomposites
}

\author{
Sophia Sachse, ${ }^{1}$ Francesco Silva, ${ }^{1}$ Huijun $\mathrm{Zhu},{ }^{2}$ Adeel Irfan, ${ }^{2}$ \\ Agnieszka Leszczyńska, ${ }^{3}$ Krzysztof Pielichowski, ${ }^{3}$ Valentina Ermini, ${ }^{4}$ \\ Maria Blazquez, ${ }^{5}$ Oleksandr Kuzmenko, ${ }^{6}$ and James Njuguna ${ }^{1}$ \\ ${ }^{1}$ Department of Environmental Science and Technology, Cranfield University, Bedfordshire MK43 OAL, UK \\ ${ }^{2}$ Cranfield Health, Cranfield University, Bedfordshire MK43 OAL, UK \\ ${ }^{3}$ Department of Chemistry and Technology of Polymers, Cracow University of Technology, 31-155 Krakow, Poland \\ ${ }^{4}$ R\&D Department, Laviosa Chimica Mineraria, Via Leonardo da Vinci, 21 I-57123 Livorno, Italy \\ ${ }^{5}$ RTD Department, INKOA SISTEMAS, SL, Bizkaia, 48950 Erandio, Spain \\ ${ }^{6}$ Palladin Institute of Biochemistry, The National Academy of Sciences of Ukraine, 9 Leontovicha Street, Kiev 01601, Ukraine
}

Correspondence should be addressed to James Njuguna, j.njuguna@cranfield.ac.uk

Received 20 January 2012; Revised 3 April 2012; Accepted 6 April 2012

Academic Editor: Sevan P. Davtyan

Copyright () 2012 Sophia Sachse et al. This is an open access article distributed under the Creative Commons Attribution License, which permits unrestricted use, distribution, and reproduction in any medium, provided the original work is properly cited.

\begin{abstract}
During the past decade, polymer nanocomposites have emerged as a novel and rapidly developing class of materials and attracted considerable investment in research and development worldwide. However, there is currently a lack of information available in the literature on the nano and ultrafine particle emission rates from these materials. In this paper, influence of nanoclay on mechanical drilling of PA6 composites, in terms of dust generation, has been reported. With the help of real-time characterization, submicrometer-sized particles $(5.6-512 \mathrm{~nm})$, size distribution, and number concentration emitted from polyamide 6/nanoclay composites during mechanical drilling are studied. Total particle concentration for the PA6/nanoclay composites was $20,000 \mathrm{~cm}^{-3}$, while unreinforced panel measured a total concentration of approximately $400,000 \mathrm{~cm}^{-3}$. While the airborne particle concentration for the PA6/nanoclay composites was 20 times lower than for the PA6 matrix, the concentration of deposited nanoparticles doubled for the nanocomposite. The results clearly show that more particles in the size range between 175 and 350 nm are generated, during drilling of the nanocomposites, and these particles deposit in a shorter time. It is likely that the presence of nanoclay in some way retains the formation of high quantity of airborne particles and promotes particle deposition.
\end{abstract}

\section{Introduction}

Nanoreinforced polymers have focused the attention, because of their potential to exhibit impressive enhancements of material properties compared to the pure polymers. For light weight constructions, among various nanocomposites, much attention has been paid to polymer/layered silicate nanocomposites, because of their enhanced mechanical properties, high thermal stability, and high flame retardancy [1-7]. Nanoclays account for approximately $70 \%$ of the total volume of nanomaterials commercially used [8]. In the automotive and packaging sector nanoclays were introduced, mainly due to their low cost and availability. Poly(methyl methacrylate)—epoxy—nanoclay composites
[9], polypropylene-nanoclay composites [10], polyvinylidene fluoride - nanoclay nanocomposites [11], and nanoclay modified rigid polyurethane foam [12] exhibit improved properties when compared to their bulk polymer constituents and conventional macrocomposite counterparts. Numerous studies have reported the improvement of energy absorption of nanoclay/polymer nanocomposites [13-15]. For example, John et al. [16] have shown that the incorporation of 2 and 4 vol.\% of nanoclay, respectively, improves the tensile modulus of cyanate ester syntactic foams by 60 and $80 \%$, respectively.

On the other hand, only little attention has been paid to the behaviour of these materials on the emission of free nanofiller as ultrafine airborne particles during their life 


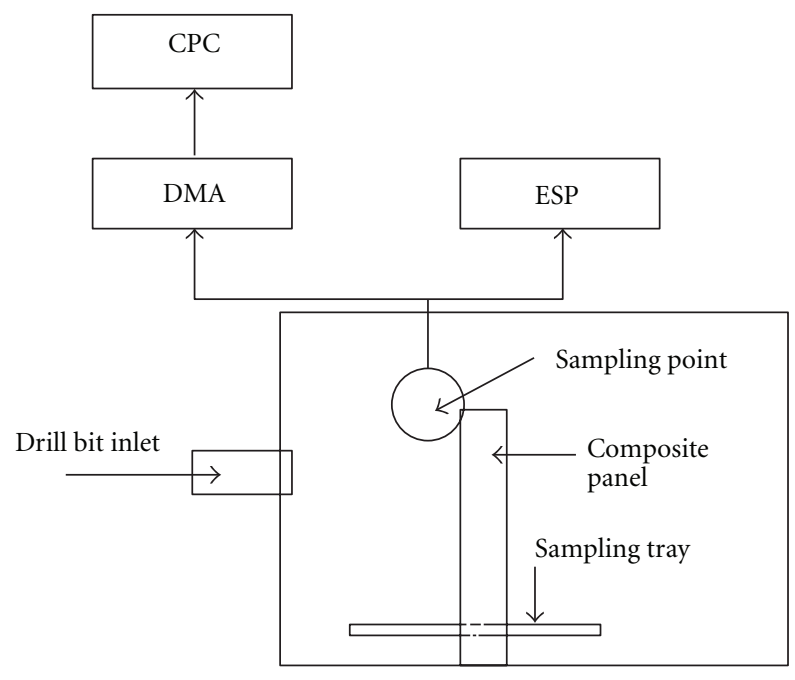

FIgURE 1: Apparatus and setup for the chamber experiments.

time. Shear forces during different mechanical processes such as milling, grinding, turning, boring, and drilling may detach free nanofiller as ultrafine airborne particles. Due to their size, these particles are able to remain airborne for a longer period [17] and are suspected to enter the human cells more easily via respiratory, dermal, or oral absorption [18, 19]. The high biological activity can be explained by the large surface-to-volume ratio; hence many types of nanoparticles have shown toxic impact [20-23].

In the current work, airborne particles emitted by nanoclay filled polyamide 6 nanocomposites during mechanical drilling, in a controlled environment, were investigated. The particle number concentration and size distribution were measured continuously in real time using a particle sizer. In addition, the particles emission rates were evaluated, as this information could be useful in assessing the particle exposure to air. Further, deposited particles were collected and investigated utilising a nanoparticle tracking analysis and electron microscopy, for assessing the emission of particles to soil and water.

\section{Experimental}

2.1. Materials. Polyamide 6 (PA-6) Tarnamid T30, Azoty Tarnów, Poland (melt volume flow rate $25.0 \mathrm{~g} / 10 \mathrm{~min}$ $\left.\left(275^{\circ} \mathrm{C} / 5.0 \mathrm{~kg}\right)\right)$, due to its respectable mechanical properties, was chosen as an appropriate matrix material. As filler materials 5 wt.\% of montmorillonite (Laviosa/Dellite 43B) was used, which has been surface modified with N,N-dimethyl-N-benzyl-N-octadecyl ammonium utilization. The montmorillonite (MMT) was first dispersed in hot distilled water at a concentration of max. $5 \mathrm{wt} \%$ and mixed at $70^{\circ} \mathrm{C}$ for $2 \mathrm{~h}$. Subsequently, a water solution of cationic surfactant $\left(\mathrm{R}=\right.$ alkyl chain $\left.\mathrm{C}_{16}-\mathrm{C}_{18}\right)$ was slowly added in an adequate quantity for cation exchange of MMT. The mixture was stirred for $3 \mathrm{~h}$ to enable complete sodium cation exchange. Then the precipitate was filtered and washed with hot distilled water until no chloride ions were detected in the filtrate after addition of $0.1 \mathrm{~mol} \mathrm{AgNO}_{3}$. Finally, the filtered cake was dried, grounded into fine powder, and size-graded with a $50 \mu \mathrm{m}$ sieve.

2.2. Manufacturing of Polyamide 6/Nanoclay Composites Panels. Compounding of the composite material was conducted in a twin-screw extruder (ZMK/116/10, ZAMAK-Cable Machinery Plant, Poland). The PA6 and $5 \mathrm{wt}$ \% of organically modified montmorillonite were premixed and batched by the main feeder to the first barrel zone. The extruder was equipped as follows: screw diameter $24 \mathrm{~mm}$, length/diameter ratio 32, conventional screw configuration, and 6 barrel zones with two high-shearing zones. This granulate was then used for nanocomposite manufacturing by compression moulding.

The mould temperature was kept at $250^{\circ} \mathrm{C}$ over the compression time of $5 \mathrm{~min}$. Due to the high dimensions of the panels, cooling of the polymer melt was completed in the mould in order to avoid material warping.

2.3. Drilling Experiment. Drilling of the nanoreinforced panels was conducted in a controlled environment, with just one small opening for the drill bit $(10 \mathrm{~mm}$ diameter $)$ as shown in Figure 1. This chamber was designed to reduce the possible influence of the drilling engine, as background noises, on the measurement results. Inside the chamber the composite panels were mounted on a fixture. A sampling tray helped collecting the turnings which were produced during drilling. The measurement equipment and the chamber were connected with help of an antistatic silicon tube. An angle drill (Makita BDA351Z 18V LXT Angle Drill) was used for drilling with a maximum speed of $1800 \mathrm{~min}^{-1}$. Before the drilling experiment, the chamber was purged with laboratory air for about $20 \mathrm{~min}$. Each sampling cycle comprised a $60 \mathrm{~min}$ background air monitoring in the chamber, $14 \mathrm{~min}$. of active drilling, and a $60 \mathrm{~min}$ postdrilling period. The experiment was repeated 3 times for each material composition.

Airborne particle size distributions were measured with help of an SMPS+C (Condensation Particle Counter "CPC" 5.403 with Classifier "Vienna"-DMA 5.5-U, Grimm Aerosol, Germany). An Electrostatic Precipitator (Model 5.561 Grimm Aerosol, Germany) was utilized to sample the generated airborne particles. A high voltage $(5000 \mathrm{~V})$ was applied to the central electrode to attract the charged particles onto a sampling plate. The particles on the sampling plate were then studied in further scanning electron microscope analysis.

Fracture particles were sampled in a dry state and analysed by suspending them in solution. Particle size distribution and quantity were measured by nanoparticle tracking analysis (NTA) provided by the Nanosight equipment (Model LM20, NanoSight Ltd.). A defined mass of fracture particles $(0.30 \mathrm{~g})$ were suspended in $20 \mathrm{~mL}$ of deionised water, this solution was then introduced to the Nanosight equipment using a disposable syringe. For the TEM images, $30 \mathrm{mg}$ of fracture particles were suspended in $1 \mathrm{~mL}$. After sonification, $0.5 \mathrm{~mL}$ of this suspension was used for TEM study. 

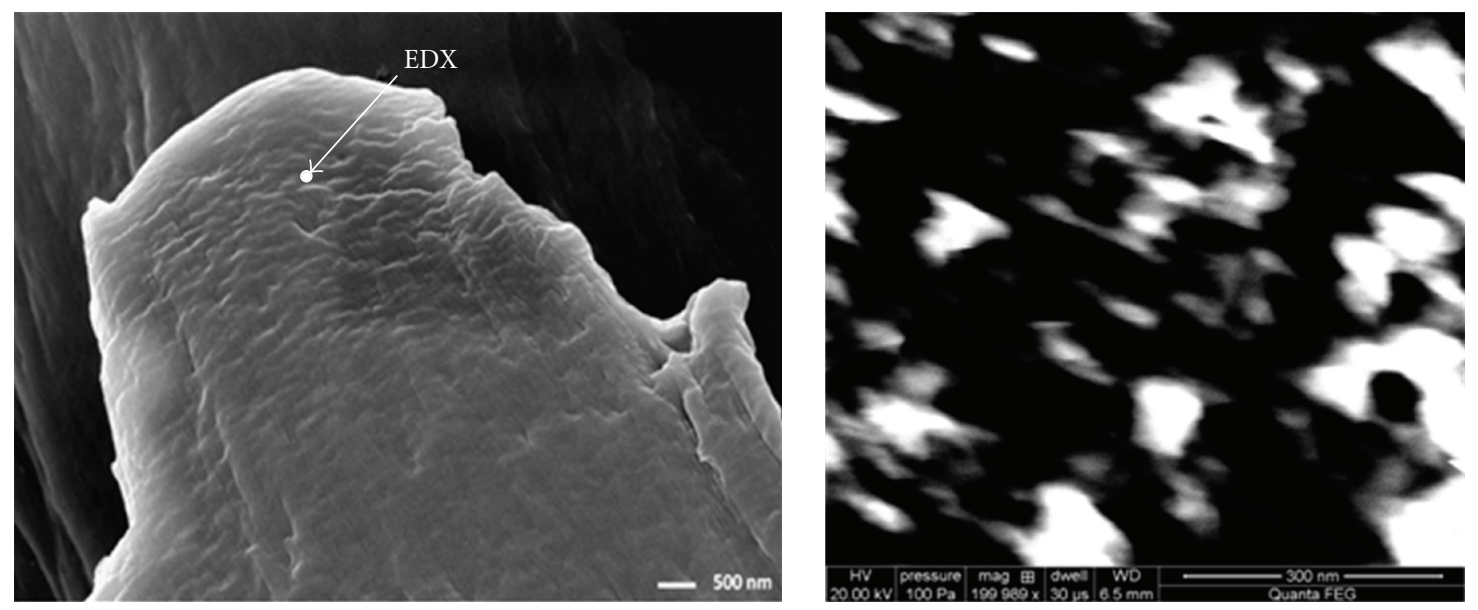

(a)

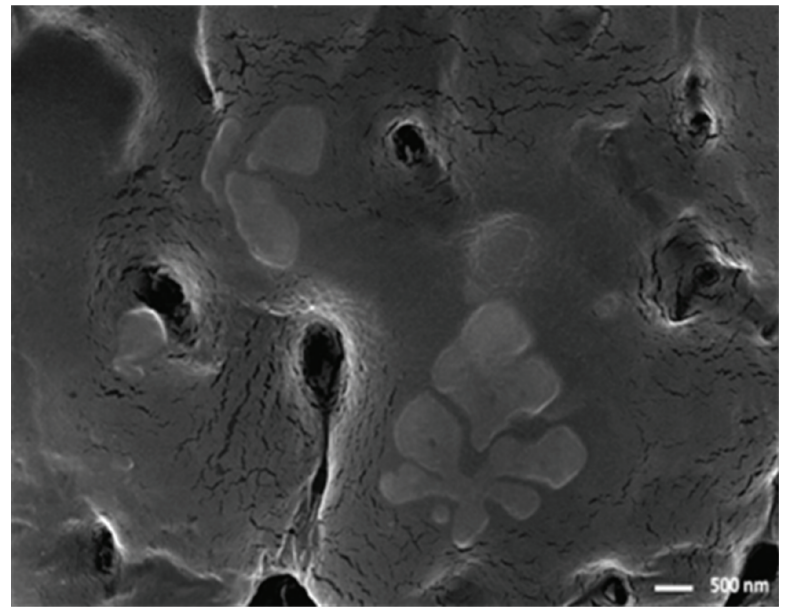

(b)

FIgURE 2: SEM micrographs of bulk: (a) nanoreinforced composites and (b) virgin material.

2.4. Material Characterisation. The morphology of the nanocomposites was investigated by using an FEI XL30 field emission scanning electron microscope (SEM). The operating voltage was in the range of $10-20 \mathrm{kV}$, and the specimens were gold sputtered to minimize charging of the sample.

Crystalline structure of the manufactured nanocomposites was studied with help of powder X-ray diffraction (XRD). XRD studies were performed between $1-10^{\circ}$ and $3-$ $60^{\circ}$ scattering angle, using a Philips X-Pert diffractometer, with graphite monochromator placed in the front of detector- $\lambda_{\mathrm{Cu}}=1.5418 \AA$.

\section{Results and Discussion}

3.1. Morphology of Nanocomposite Panels. Microscopical investigation of the nanoadditive panels did not show microscopic agglomerates of filler as shown in Figure 2(a). The PA6/nanoclay composites showed formation of a net of inclusions (brighter areas) of nanometric dimensions (Figure 2(a)). The various shapes of inclusions (both anisometric and isometric) reflect limited orientation of nanoparticles in the core region of the moulded sample and an anisotropic structure. The observations of structure and morphology of PA6/nanoclay composites by SEM technique enabled to confirm the uniform distribution of nanoparticles in polymer matrix. The morphology of the PA6 panels has shown dendrite structures in some areas. One reason for this dendritic growth was caused from growth instabilities that occurred when the growth rate was limited by the rate of diffusion of solute atoms to the interface [24].

WAXD diffractogram of the neat material reflected a strong diffraction peak with a maximum at $21.5^{\circ}$, which corresponded to the $\gamma$ crystalline phase, and small peak at $37.9^{\circ}$. The main diffraction peak observed on WAXD diffractogram of the PA6/nanoclay composites panels occurred at the same value of $2 \theta$ degree as for neat PA6 matrix (Figure 3(a)). Therefore, no significant changes in the matrix's crystallographic structure were induced by nanofiller in the prepared panels. The formation of a nanostructure was additionally confirmed by SAXD method (Figure 3(b)). The characteristic peaks for organically modified MMT disappeared completely in the nanocomposite indicating significant alteration of the original parallel arrangement of nanoclay layers. 


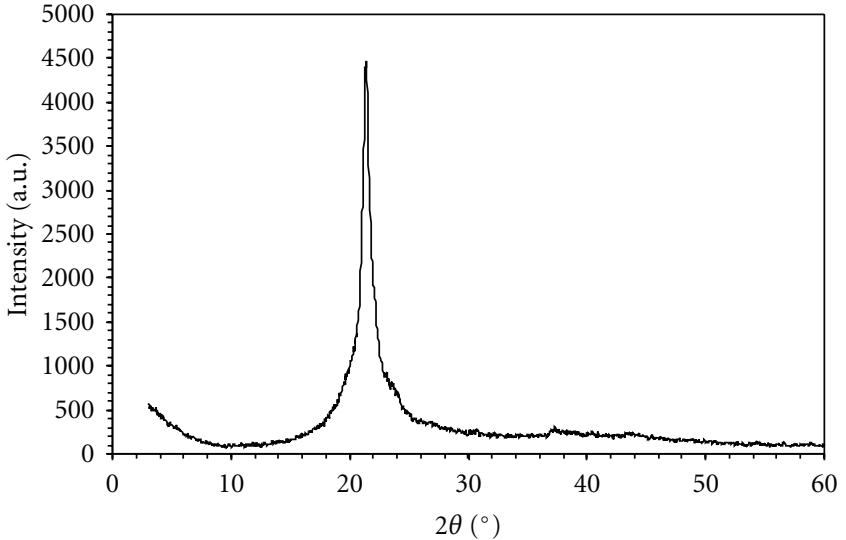

— PA6-MMT

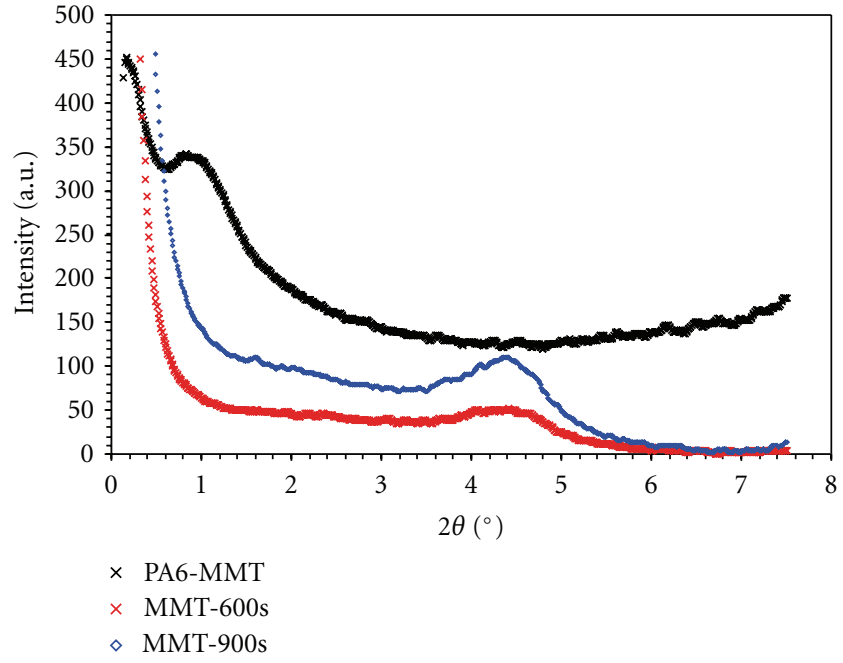

(b)

FIgURE 3: (a) WAXD diffractogram of PA6/nanoclay composites. (b) SAXD PA6/nanoclay composites and organically modified MMT.

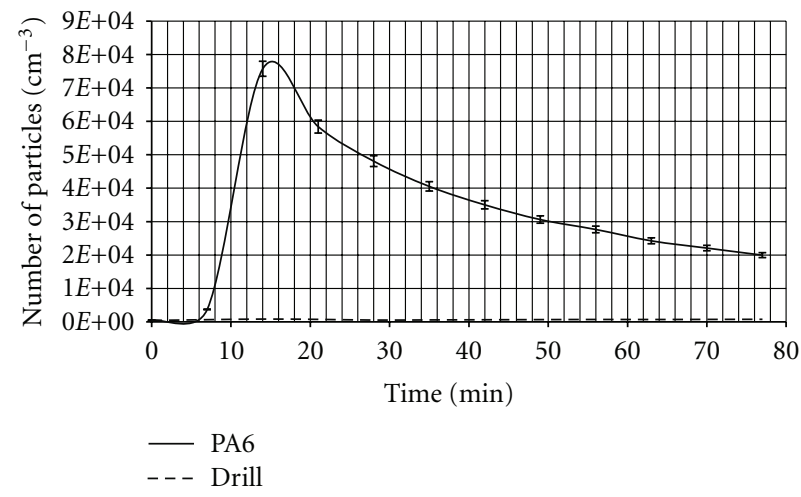

(a)

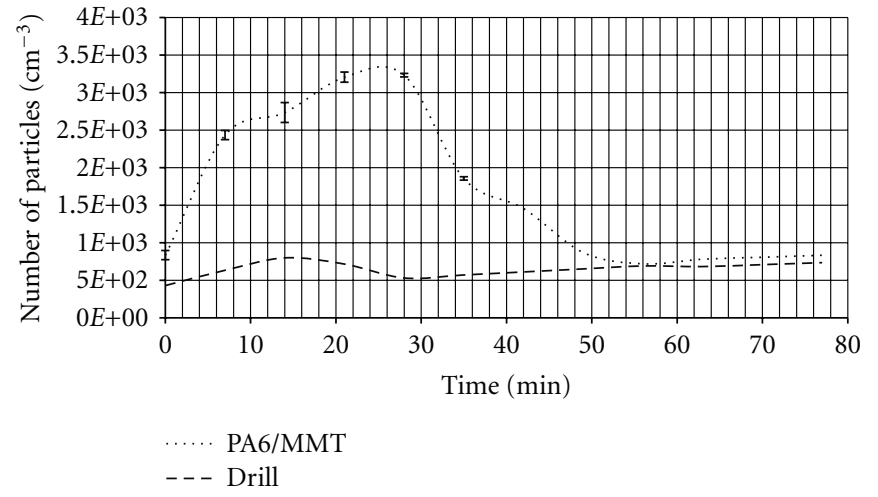

(b)

FIGURE 4: Sequential alteration of number concentration of a typical sampling cycle for neat PA6 (a) and PA6/MMT composite (b).

3.2. Nanoscale Dust Particles during Drilling. The sequential alteration of the total number concentration of airborne particles, for a typical sampling cycle, is shown in Figure 4. The total number concentration was essentially constant with an average of 1000 (particles $/ \mathrm{cm}^{3}$ ) before drilling. As soon as drilling started, the number concentration increased rapidly. The maximum number concentration was reached for the virgin material as soon as drilling was terminated and after approximately $30 \mathrm{~min}$ for the PA6/nanoclay composites panel. Subsequently, the particle decay was observed with the concentration falling back to the original background level approximately after a postdrilling period of $2 \mathrm{~h}$. In significant research studies [25-30] the influence of the machining engines as "background noises" on the results has been reported. As the drilling was conducted in a controlled environment, the influence of the machining engine could be reduced to a minimum. Compared with the total particle concentration the particles generated by the drill are minimal and therefore were neglected. The total concentration was around $20,000 \mathrm{~cm}^{-3}$ for the nanoclay filled panel, while the unreinforced panel measured a total concentration of approximately $400,000 \mathrm{~cm}^{-3}$. As the total concentration was 20 times lower for the reinforced panel, it is likely that the presence of nanoclay in some way retains the formation of high quantity of airborne particles.

Diffusion, gravitational deposition, convection, impaction, and coagulation are some of the complex processes which influence formation and removal of particles in the chamber. Removal of small particles is primarily dominated by diffusion while larger particles are mainly affected by gravitation. During diffusion, small particles collide with one another and form larger particles. This process is known as coagulation and strongly depended on particle size and concentration. An indication of the coagulation rate can be stated identified by the half-life of an individual particle, which is introduced into an atmosphere embracing a defined concentration of such particles [31]. However, coagulation can be neglected for laboratory experiments if the particle 


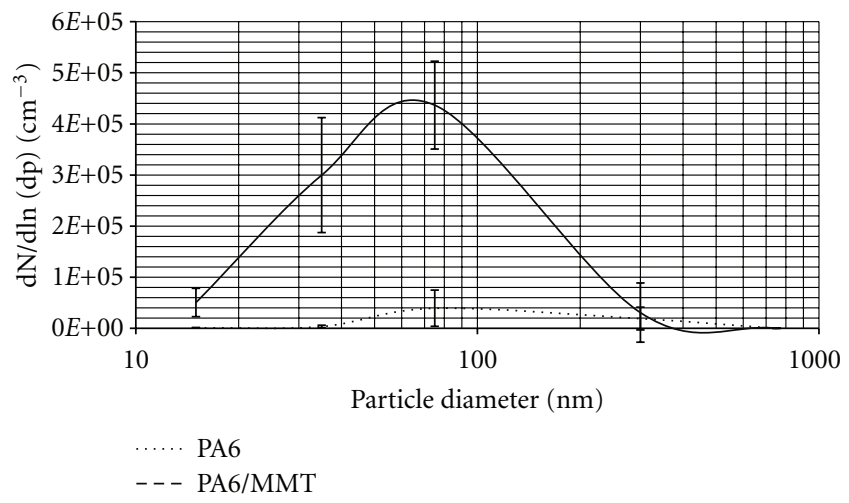

FIGURE 5: Normalized particle size distributions at ending of the drilling cycles.

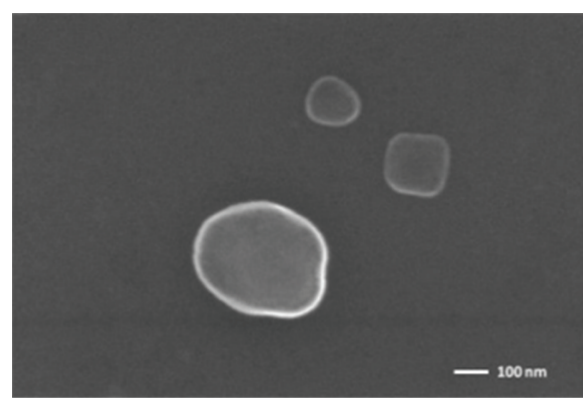

(a) PA6/nanoclay-particle

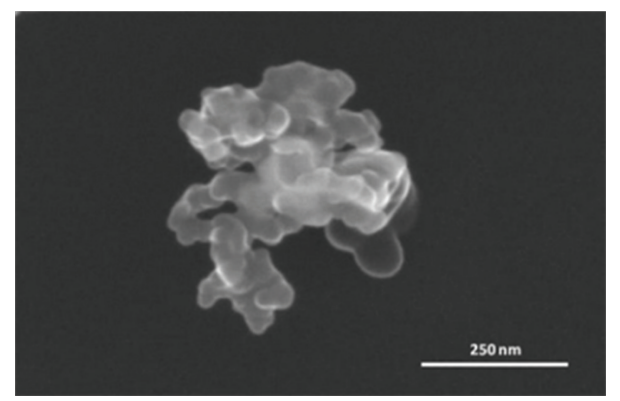

(b) PA6-particle

FIgURE 6: SEM micrographs of (a) PA6/nanoclay-particle and (b) PA6-particle collected by ESP.

concentration was less than $1 \times 10^{12} \mathrm{~m}^{-3}$. As the maximum concentration measured in this study did not exceed $3.86 \times$ $10^{11} \mathrm{~m}^{-3}$, coagulation could be neglected [32].

The particle size distributions of drilling into different material systems are shown in Figure 5. The plots which reflected particle size distributions at the time particle concentration reached its maximum, and drilling was terminated. The plots presented the normalized distribution with $\Delta \mathrm{N} / \Delta \operatorname{lndp}$ versus the particle diameter $\mathrm{dp}$, where $\Delta \mathrm{N}$ is the concentration of particles within a specified size interval and $\Delta \operatorname{lndp}$ is the difference in the natural logarithm of the largest and smallest particle sizes of that interval. From visual inspection of the graph, it could be noted that the modal diameters were the same for unreinforced and reinforced composite panel. Similar results were obtained by Wohlleben et al. [27], while comparing nanocomposites with their reference materials without nanofillers, that the differences are insignificant in the actual size distribution of aerosols during normal abrasion use. However, they [27] also reported no significant changes between reference materials without nanofillers in the number concentrations, which could not be confirmed by the results we obtained.

To support the measurements obtained by SMPS $+\mathrm{C}$, particles were sampled via electrostatic precipitators (ESPs, Grimm Aerosols, Germany) and subjected to JFEI XL30 field emission scanning electron microscope. The scanning electron micrographs of the particles generated during drilling of different composites are represented in Figure 6.
Micrographs of the particles generated from PA6 panels showed coagulation of small particles $(80 \mathrm{~nm})$ to larger particles $(300 \mathrm{~nm})$. Microscopic investigation of the particles obtained from drilling PA6/nanoclay composites was scattered over the sampling plate, and no coagulation could be found. According to Grassian [31] the half time of particles in the size range of $10-200 \mathrm{~nm}$ in the measured concentration would be between 16 and $83 \mathrm{~min}$, therefore coagulates of particles are natural for a sampling period of $2 \mathrm{~h}$.

As there was a major difference between the particles emitted during drilling of nanofilled PA6 and virgin PA6, particles which deposited on the sampling tray inside the chamber were investigated. Total deposited particles concentration and geometric mean size were measured by Nanosight, after suspending the dry collected particles in deionised water nanoclay filled PA6 specimen, which was double the concentration of the unfilled PA6. This meant that PA6/ nanoclay composites generated more particles that deposited, compared to the unreinforced material especially in the size range between 175 and $350 \mathrm{~nm}$.

The scanning and transmission electron microscopy micrographs confirmed the Nanosight results, as shown in Figure 7. The airborne nanoscale particle concentration of the PA6/nanoclay composites was lower than for the virgin matrix material, and the deposited concentration was higher. An increase in the aerodynamic diameter of particle size results in an increase in the rate of deposition due to gravitational effects. 

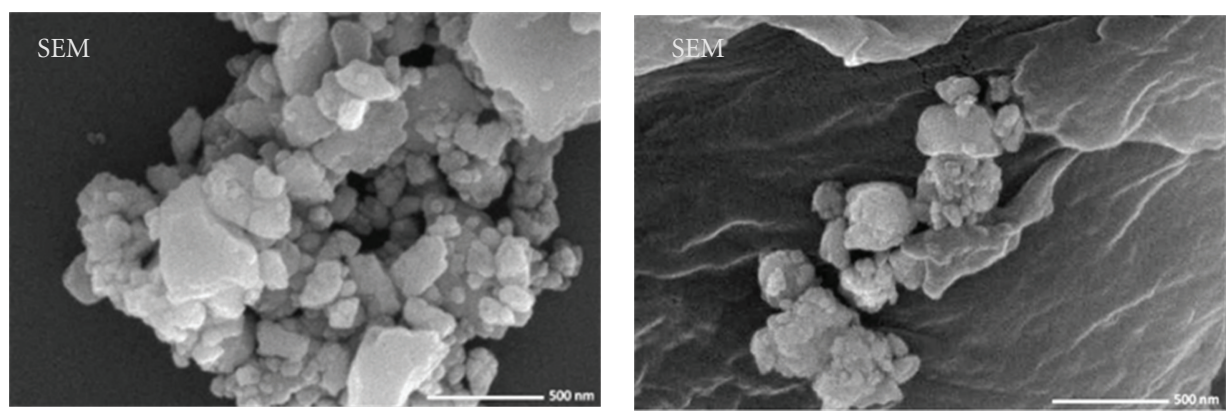

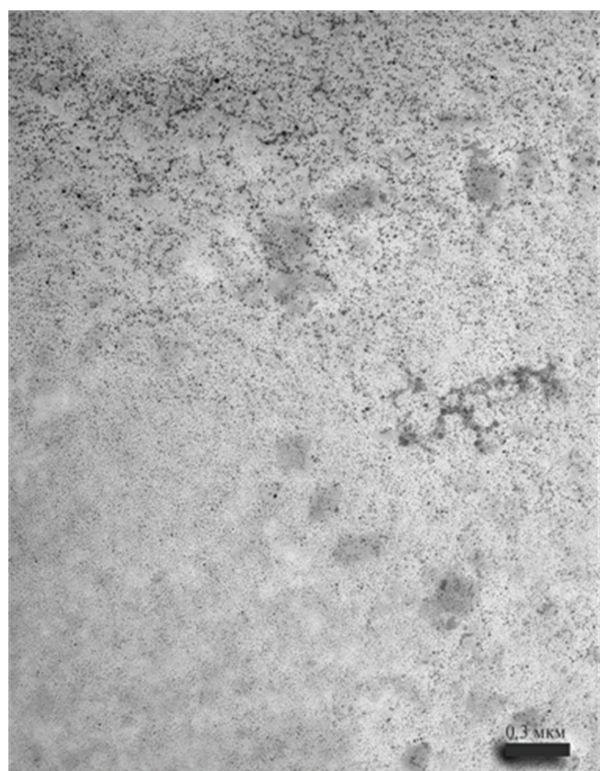

(a) PA6/nanoclay-particle

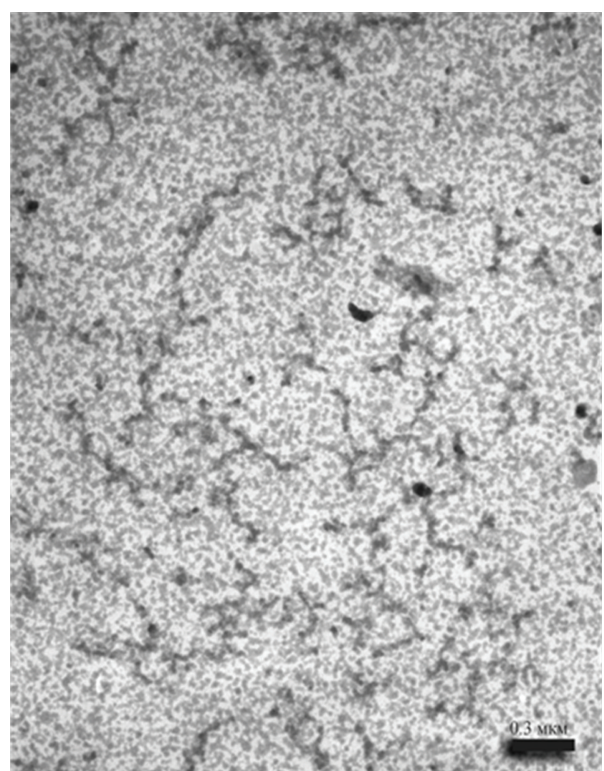

(b) PA6-particle

Figure 7: SEM/TEM micrographs of (a) PA6/nanoclay-particle and (b) PA6-particle.

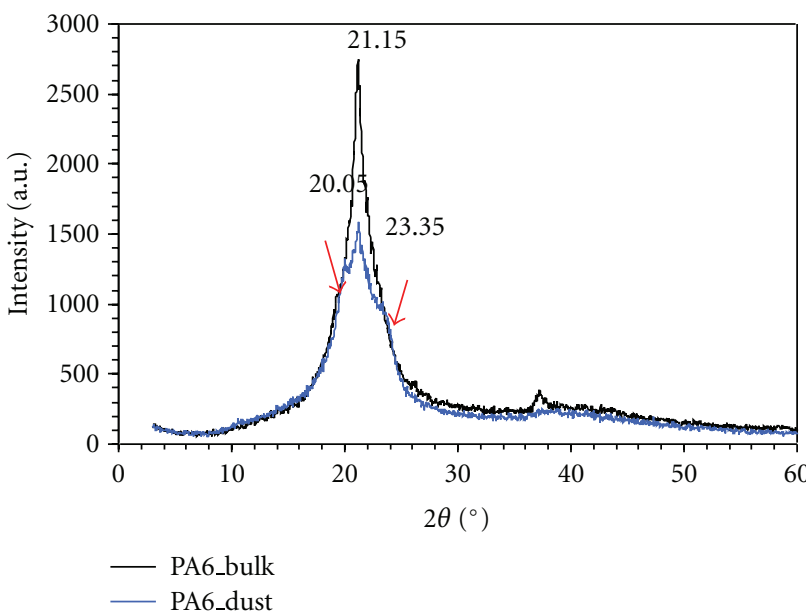

(a)

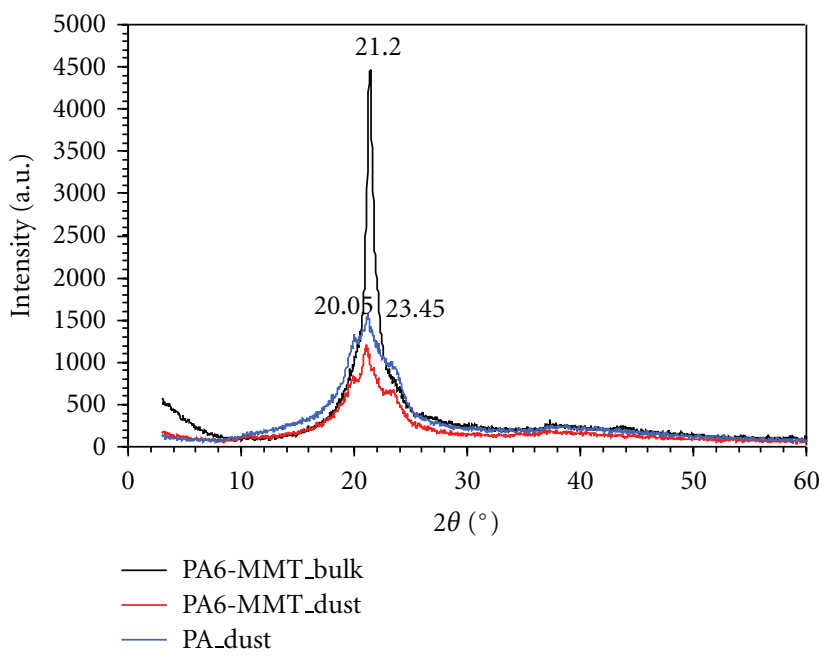

(b)

FIGURE 8: WAXD diffractograms of (a) PA6 bulk panel and generated particles and (b) PA6/nanoclay bulk panel and generated particles. 
The diffraction pattern of PA6 in a bulk form and a powder are presented in Figure 8. Clearly the polymorphic structure was formed under the action of mechanical force since one strong peak corresponding to the $\gamma$ crystalline phase of PA6 in bulk form was weakened after drilling and additional peaks at $20.05^{\circ}$ and $23.35^{\circ}$ occur showing the formation of $\alpha$-crystal phase of PA6. Recrystallization of polymer matrix may be facilitated by the heat evolved during mechanical drilling of the polymer materials.

\section{Conclusions}

Nanoclay filled PA6 nanocomposites were manufactured through direct compounding and compression moulding process. Microscopic analysis of the nanocomposites morphology revealed that the nanoclay was dispersed homogeneously throughout the PA6 matrix. Additional WAXD analysis showed a high degree of exfoliation of the nanoclay in the polymeric matrix. The investigating particle released from PA6 and PA6/nanoclay composites during drilling demonstrated that the airborne particle concentration was decreased by integration of nanofillers in the matrix.

However, while the airborne particle concentration for the PA6/nanoclay composites was 20 times lower than for the PA6 matrix, the concentration of deposited nanoparticles doubled for the nanocomposite. The results showed that more particles in the size range between 175 and $350 \mathrm{~nm}$ are generated and these particles deposit in a shorter time. The results showed that drilling of nanocomposites generates nanoparticles; therefore, this should be considered and assessed while dealing with machining of nanocomposites. However, it could also be shown that by integration of nanoclay into the PA6 matrix airborne particle quantity can be reduced.

\section{Acknowledgment}

This work was funded by the European Commission (FP7 NEPHH Project-CP-FP; Project Reference no. 228536-2).

\section{References}

[1] M. Kawasumi, N. Hasegawa, M. Kato, A. Usuki, and A. Okada, "Preparation and mechanical properties of polypropylene-clay hybrids," Macromolecules, vol. 30, no. 20, pp. 6333-6338, 1997.

[2] S. C. Tjong, "Structural and mechanical properties of polymer nanocomposites," Materials Science and Engineering R, vol. 53, no. 3-4, pp. 73-197, 2006.

[3] D. Shah, P. Maiti, E. Gunn et al., "Dramatic enhancements in toughness of polyvinylidene fluoride nanocomposites via nanoclay-directed crystal structure and morphology," Advanced Materials, vol. 16, no. 14, pp. 1173-1177, 2004.

[4] F. Bensadoun, N. Kchit, C. Billotte, F. Trochu, and E. Ruiz, "A comparative study of dispersion techniques for nanocomposite made with nanoclays and an unsaturated polyester resin," Journal of Nanomaterials, vol. 2011, Article ID 406087, 12 pages, 2011.

[5] J. Njuguna, F. Silva, and S. Sachse, "Nanocomposites for vehicle structural applications," in Nanofibers, Production, Properties and Functional Applications, pp. 402-434, InTech Press, 2011.
[6] N. Sheng, M. C. Boyce, D. M. Parks, G. C. Rutledge, J. I. Abes, and R. E. Cohen, "Multiscale micromechanical modeling of polymer/clay nanocomposites and the effective clay particle," Polymer, vol. 45, no. 2, pp. 487-506, 2004.

[7] J. Njuguna, S. Sachse, A. Ifran, H. Zhu, S. Michalowski, and K. Pielichowski, Modern Polymeric Materials for Environmental Applications, vol. 4, 2010.

[8] BCCResearch, Nanotechnology—Research, 2010.

[9] J. H. Park and S. C. Jana, "The relationship between nano- and micro-structures and mechanical properties in PMMA-epoxynanoclay composites," Polymer, vol. 44, no. 7, pp. 2091-2100, 2003.

[10] G. Galgali, S. Agarwal, and A. Lele, "Effect of clay orientation on the tensile modulus of polypropylene-nanoclay composites," Polymer, vol. 45, no. 17, pp. 6059-6069, 2004.

[11] D. R. Dillon, K. K. Tenneti, C. Y. Li, F. K. Ko, I. Sics, and B. S. Hsiao, "On the structure and morphology of polyvinylidene fluoride-nanoclay nanocomposites," Polymer, vol. 47, no. 5, pp. 1678-1688, 2006.

[12] T. Widy and C. W. Macosko, "Nanoclay-modified rigid polyurethane foam," Journal of Macromolecular Science, Part B Physics, vol. 44, pp. 897-908, 2005.

[13] B. Chen and J. R. G. Evans, "Impact and tensile energies of fracture in polymer-clay nanocomposites," Polymer, vol. 49, no. 23, pp. 5113-5118, 2008.

[14] K. Sterky, H. Jacobsen, I. Jakubowicz, N. Yarahmadi, and T. Hjertberg, "Influence of processing technique on morphology and mechanical properties of PVC nanocomposites," European Polymer Journal, vol. 46, no. 6, pp. 1203-1209, 2010.

[15] J. Njuguna, K. Pielichowski, and S. Desai, "Nanofillerreinforced polymer nanocomposites," Polymers for Advanced Technologies, vol. 19, no. 8, pp. 947-959, 2008.

[16] B. John, C. P. Reghunadhan Nair, and K. N. Ninan, "Effect of nanoclay on the mechanical, dynamic mechanical and thermal properties of cyanate ester syntactic foams," Materials Science and Engineering, A, vol. 527, no. 21-22, pp. 5435-5443, 2010.

[17] R. M. Harrison, "Key pollutants—airborne particles," Science of the Total Environment, vol. 334-335, pp. 3-8, 2004.

[18] G. A. Sotiriou, E. Diaz, M. S. Long et al., "A novel platform for pulmonary and cardiovascular toxicological characterization of inhaled engineered nanomaterial," Nanotoxicology. In press.

[19] W. Yang, J. I. Peters, and R. O. Williams, "Inhaled nanoparticles-a current review," International Journal of Pharmaceutics, vol. 356, no. 1-2, pp. 239-247, 2008.

[20] W. Yang, J. I. Peters, and R. O. Williams, "Inhaled nanoparticles-a current review," International Journal of Pharmaceutics, vol. 356, no. 1-2, pp. 239-247, 2008.

[21] K. L. Dreher, "Health and environmental impact of nanotechnology: toxicological assessment of manufactured nanoparticles," Toxicological Sciences, vol. 77, no. 1, pp. 3-5, 2004.

[22] G. Oberdrster, "Safety assessment for nanotechnology and nanomedicine: concepts of nanotoxicology," Journal of Internal Medicine, vol. 267, no. 1, pp. 89-105, 2010.

[23] A. D. Maynard, D. B. Warheit, and M. A. Philbert, "The new toxicology of sophisticated materials: nanotoxicology and beyond," Toxicological Sciences, vol. 120, supplement 1, pp. S109-S129, 2011.

[24] K. Kassner, Pattern Formation in Diffusion-Limited Crystal Growth, World Scientific, Singapore, 1996.

[25] I. K. Koponen, K. A. Jensen, and T. Schneider, "Sanding dust from nanoparticle-containing paints: physical characterisation," Journal of Physics: Conference Series, vol. 151, no. 1, Article ID 012048, 2009.

[26] K. A. Jensen, I. K. Koponen, P. A. Clausen, and T. Schneider, "Dustiness behaviour of loose and compacted Bentonite and 
organoclay powders: what is the difference in exposure risk?" Journal of Nanoparticle Research, vol. 11, no. 1, pp. 133-146, 2009.

[27] W. Wohlleben, S. Brill, and M. W. Meier, "On the lifecycle of nanocomposites: comparing released fragments and their in-vivo hazards from three release mechanisms and four nanocomposites," Small, vol. 16, pp. 2384-2395, 2011.

[28] D. Bello, B. L. Wardle, N. Yamamoto et al., "Exposure to nanoscale particles and fibers during machining of hybrid advanced composites containing carbon nanotubes," Journal of Nanoparticle Research, vol. 11, no. 1, pp. 231-249, 2009.

[29] D. Bello, B. L. Wardle, J. Zhang et al., "Characterization of exposures to nanoscale particles and fibers during solid core drilling of hybrid carbon nanotube advanced composites," International Journal of Occupational and Environmental Health, vol. 16, no. 4, pp. 434-450, 2010.

[30] M. Vorbau, L. Hillemann, and M. Stintz, "Method for the characterization of the abrasion induced nanoparticle release into air from surface coatings," Journal of Aerosol Science, vol. 40, no. 3, pp. 209-217, 2009.

[31] V. H. Grassian, Nanoscience and Nanotechnology: Environmental and Health Impacts, John Wiley \& Sons, 2008.

[32] W. C. Hinds, "Aerosol technology: properties, behaviour, and measurement of airborne particles.," 1982. 

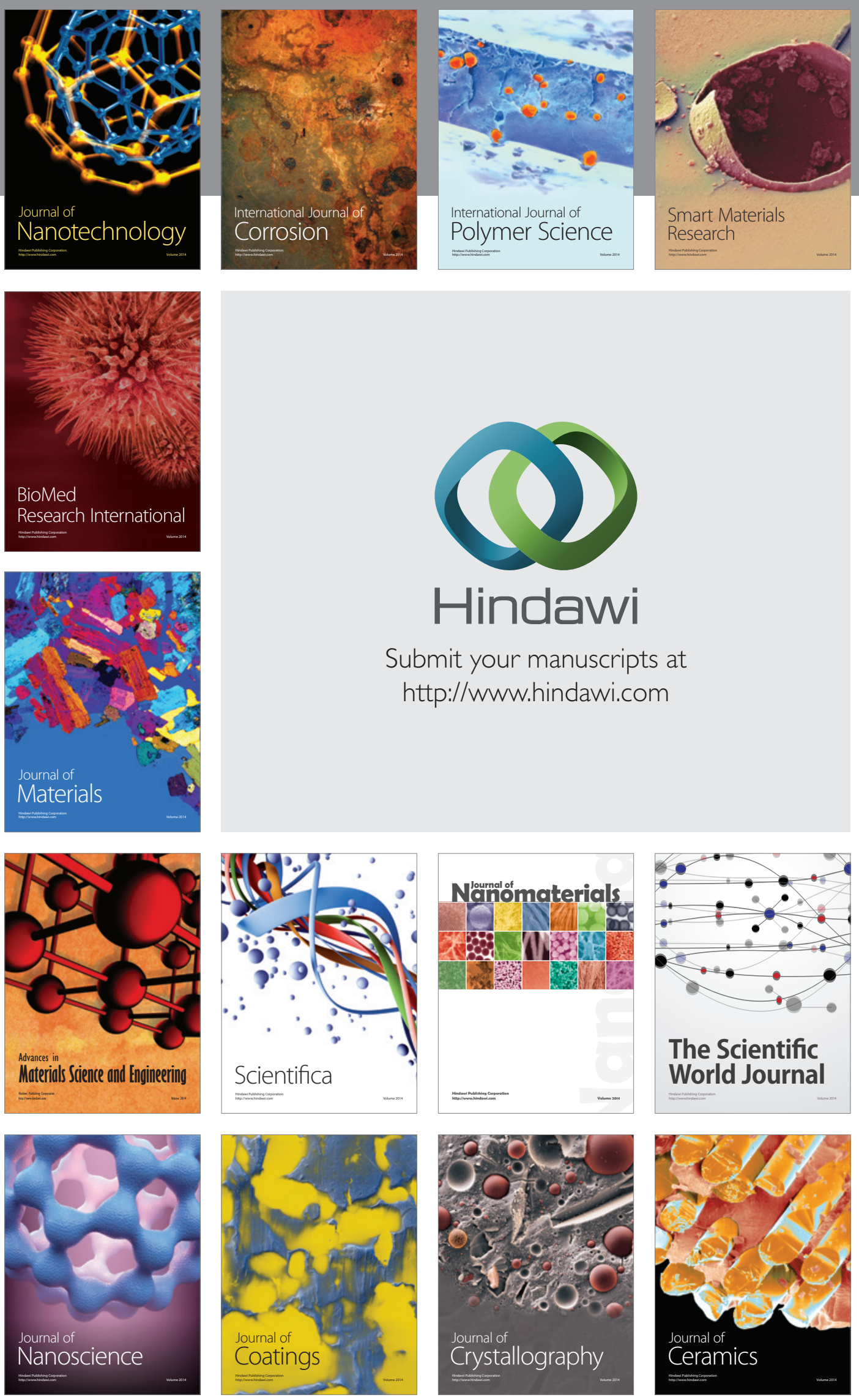

The Scientific World Journal

Submit your manuscripts at

http://www.hindawi.com

\section{World Journal}

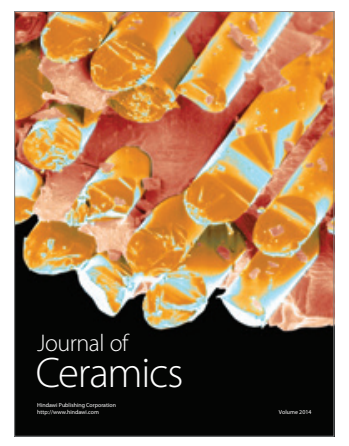

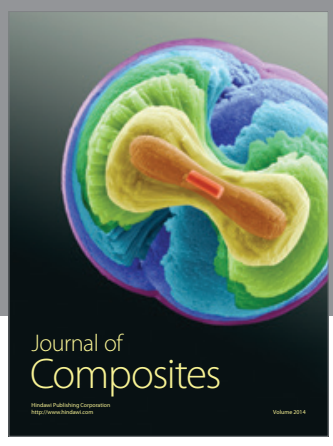
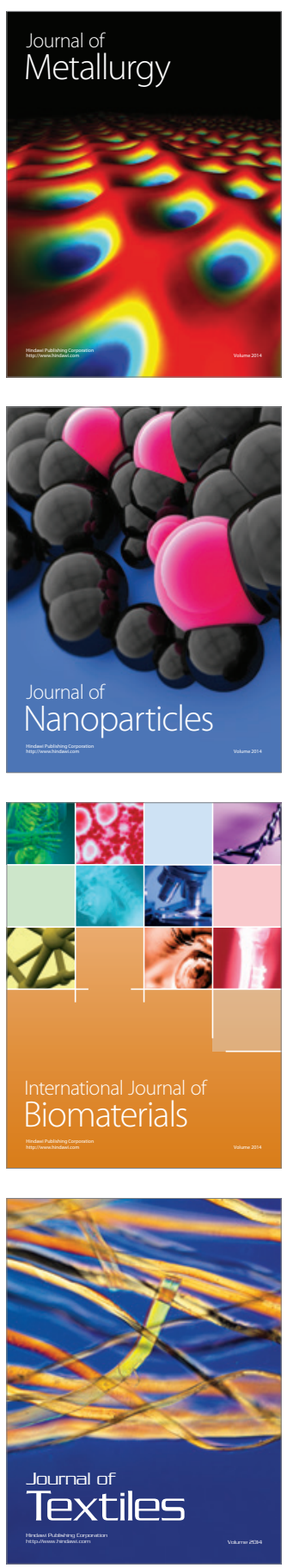